\title{
Os princípios constitucionais do processo
}

\author{
Procedural constitutional principles
}

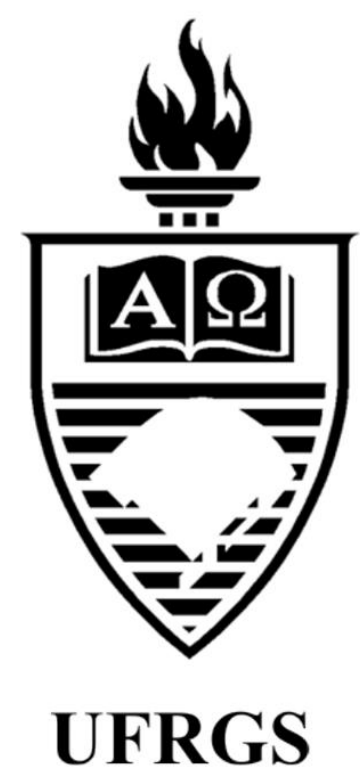

Judith Aparecida de Souza Bedê

Faculdade Autônoma de Direito de São Paulo

Thiago Ribeiro Carvalho

Faculdade Autônoma de Direito de São Paulo 


\title{
Os princípios constitucionais do processo
}

\author{
Procedural constitutional principles
}

Judith Aparecida de Souza Bedê*

\author{
Thiago Ribeiro Carvalho**
}

\section{REFERÊNCIA}

BEDÊ, Judith Aparecida de Souza; CARVALHO, Thiago Ribeiro. Os princípios constitucionais do processo. Revista da Faculdade de Direito da UFRGS, Porto Alegre, n. 35, vol. esp., p. 289-302, dez. 2016.

\section{RESUMO}

Este artigo aborda os princípios constitucionais do processo insculpidos na Constituição Federal brasileira de 1988, que são o contraditório, a ampla defesa, a isonomia e o devido processo legal. No trabalho constatou-se a vinculação existente entre a Constituição e o processo, que decorre da interpretação dos princípios constitucionais processuais como instituidores do processo, e sua inobservância culmina com a nulidade dos atos posteriores à violação. $\mathrm{O}$ princípio do contraditório foi abordado em suas diversas facetas, desde sua concepção à possibilidade de se contrapor ao que lhe é imputado, até a impossibilidade de a parte se ver surpreendida no decorrer do procedimento. A ampla defesa, por sua vez, foi analisada sob o aspecto da utilização de todos os meios legais para a confecção da defesa. A isonomia foi descrita como a igualdade perante a lei e de oportunidades para influenciar o provimento final. Ao final, o princípio do devido processo legal foi definido com o princípio que abrange todas as garantias constitucionais-processuais.

\section{PALAVRAS-CHAVE}

Ampla defesa. Contraditório. Devido processo legal. Isonomia.

\section{ABSTRACT}

This article approaches the procedural constitutional principles developed in the 1988 Brazilian Federal Constitution, which are the right to adversary proceedings, full defense, isonomy and due process of law. During this research it was found the connection between the Constitution and the procedure, which emerges from the interpretation of the procedural constitutional principles as builders of the process, and from its disregard follows the nullity of the acts subsequent to the breach. The principle of audi alteram partem was approached in its various aspects, since its conception to the possibility of counteract what is attributed, to the impossibility of the part to be surprised during the procedure. The full defense on the other hand was analyzed through the aspect of using all the legal ways to the preparation of the defense. The isonomy was described as equality before the law and to have opportunities to influence the outcome. At last, the principle of due process of law was described as the principle that embraces all of the constitutionalprocedural guarantees.

\section{KEYWORDS}

Full defense. Adversary proceedings. Due process of law. Isonomy.

\section{SUMÁRIO}

Introdução. 1. Constituição e processo. 2. Princípios constitucionais do processo. 2.1. Princípio do contraditório. 2.2. Princípio da ampla defesa. 2.3. Princípio da isonomia. 2.4. Considerações iniciais acerca do princípio do devido processo legal. 2.4.1. O princípio do devido processo legal na Constituição Federal de 1988. Conclusões. Referências.

\footnotetext{
* Doutoranda em Direito pela Faculdade Autônoma de Direito de São Paulo — FADISP, professora do Curso de Direito da FAFIMAN-UNIMAN e de Pós-Graduação em Maringá.

** Doutorando em Direito pela Faculdade Autônoma de Direito de São Paulo — FADISP, mestre em Direito Processual Civil pela Pontifícia Universidade Católica de Minas Gerais, especialista em Direito Processual, advogado militante e professor da Nova Faculdade de Contagem-MG.
} 


\section{INTRODUÇ̃̃O}

O objetivo deste trabalho é analisar os princípios constitucionais do processo, bem como as implicações decorrentes de sua inobservância. Por esse motivo, foi realizada uma análise dos princípios do contraditório, da ampla defesa, da isonomia e do devido processo legal, todos inscritos na Constituição Federal de 1988. Com a análise destes princípios pretendese demonstrar a importância da observância dos princípios em questão, visto que, sem a observância desses inexiste prestação jurisdicional válida.

Certamente essas garantias decorrem das grandes transformações que ocorreram com o fim da Segunda Guerra Mundial, momento em que as Constituições adquiriram uma importância ímpar na história do constitucionalismo.

Inquestionavelmente, a Constituição de 1988 foi influenciada por essas conquistas, dentre as quais certamente estão a positivação no texto constitucional dos princípios processuais, que podem ser interpretados como instituidores do processo.

O estudo se inicia com a relação existente entre o processo e a Constituição, a qual será estudada à luz da teoria constitucionalista do processo, baseada nos ensinamentos de José Alfredo de Oliveira Baracho, Andolina, Vignera e Willis Santiago Guerra Filho.

Posteriormente serão investigados os princípios institutivos do processo constitucional, que são: devido processo legal, contraditório, ampla defesa e isonomia. Ao final deste artigo, pretende-se contribuir de forma significativa para o avanço científico do tema e demonstrar a importância da observância desses ditames constitucionais.
O movimento constitucionalista posterior à Segunda Guerra Mundial elevou o processo à condição de centro irradiador e garantidor das garantias constitucionais do processo. No entanto, o processo ainda era visto como um "instrumento" a serviço do direito material.

Dentre os adeptos desse entendimento, é possível citar Eduardo J. Couture (1974, p.57), que analisa o processo constitucional como um "instrumento" a serviço do direito material. Contemporaneamente, a crítica a esse posicionamento ocorre na utilização do termo "instrumento", visto que o processo não pode ser visto simplesmente como um instrumento a serviço do direito material, conforme será demonstrado no final deste tópico.

Anos mais tarde, José Alfredo de Oliveira Baracho (1999, p. 89) propôs a substituição da visão teórica do processo como "instrumento" pela visão do processo como metodologia de garantia dos direitos fundamentais, da seguinte forma:

a) a Constituição pressupõe a existência de um processo, como garantia da pessoa humana;

b) a lei, no desenvolvimento normativo hierárquico desses preceitos, deve instituir esse processo;

c) a lei não pode conceber formas que tornem ilusória a concepção de processo consagrada na Constituição;

d) a lei instituidora de uma forma de processo não pode privar o indivíduo de razoável oportunidade de fazer valer seu direito, sob pena de ser acoimada de inconstitucional;

e) nessas condições, devem estar em jogo os meios de impugnação que a ordem jurídica local institui, para fazer efetivo o controle de constitucionalidade das leis (BARACHO, 1999, p. 89). 
também propuseram a superação da visão do processo como "instrumento", e conceituam a relação entre constituição e processo da seguinte forma: “(...) a Constituição traçou um verdadeiro modelo de processo jurisdicional, elevando o nível de garantias constitucionais em alguns pontos essenciais" (ANDOLINA, 1997, p.65). Portanto, na visão dos insignes italianos, o processo passou a ser o centro garantidor e estruturador das garantias constitucionais.

Ao se adotar essa linha teórica, tem-se o princípio do devido processo legal como gênero, do qual decorrem logicamente os seguintes direitos: a) direito constitucional de ação; b) direito constitucional de defesa; c) direito à prova e à vedação à prova ilícita; d) direito à prestação jurisdicional sem as dilações indevidas; e) direito ao recurso.

Verifica-se que, com o passar dos anos, os autores estreitaram os laços até então existentes entre a Constituição e o processo, e alguns passaram a sustentar a existência de um direito público constitucional processual, que englobaria todos os direitos alinhados anteriormente.

Paulo Bonavides (2002, p.46), que se destaca dentre os defensores dessa nova disciplina pública, traça a relação da seguinte forma: “(...) os laços do Direito Constitucional com o Direito processual se fizeram tão íntimos e apertados que dessa união parece resultar uma nova disciplina, que é o Direito Processual Constitucional".

Sob esse prisma, a validade da jurisdição está condicionada à observação dos princípios e regras constitucionais: juízo natural, ampla defesa, contraditório, isonomia e a fundamentação das decisões prolatadas nos procedimentos previstos na lei.

De forma diferente, Willis Santiago Guerra Filho (2005, p.176) sustenta que a "Constituição possui a natureza (também) de uma lei processual". Parece que, por esse entendimento, o autor vislumbra uma relação diferente da sustentada pelos autores anteriores, uma vez que o texto constitucional também contemplaria uma natureza processual.

Com o advento do CPC de 2015, o tema passou a ser discutido com maior frequência, e Daniel Mitidiero (2015, p. 51), asseverou que o novo Código introduziu o sistema processual sob a forma de modelo ou de princípio a colaboração, de forma a alterar a relação existente entre o juiz e as partes na relação processual, o que seria uma grande alteração no processo constitucional.

Ainda em relação ao processo, Daniel Mitidiero et al, 2004, p.11 informa que o processo é fruto da cultura de uma população que se desenvolveu que com o passar do tempo se viram obrigados a procurar uma forma de solucionar os conflitos. Nesse sentido, para a implementação do Estado Constitucional é necessário que os cidadãos tenham um "sentimento constitucional" e que este seja cultivado (MITIDIERO, 2007, p.27).

Em sentido diferente Fredie Didier JR (2015, p. 46) adverte que a constitucionalização do processo é um fenômeno recente, e que pode ser visto por duas dimensões: a) a inserção de normas processuais nas constituições após a $2^{\mathrm{a}}$ Guerra; e b) interpretação das normas processuais como implementadoras das normas constitucionais.

Todavia, apesar dos ensinamentos dos insignes autores este trabalho adota como referência teórico os ensinamentos de Rosemiro Pereira Leal, que sustenta que a relação entre Constituição e processo é a de uma instituição constitucionalizada, em que o procedimento deve observar os princípios instituidores do processo, a saber: o princípio do contraditório, o princípio da ampla defesa e o princípio da isonomia (LEAL, 2002, p.86).

Neste diapasão, o processo se torna o meio constitucional de criação, revisão (processo legislativo) e aplicação (processo jurisdicional), 
e cuja validade está condicionada à observância dos princípios constitucionais.

Por fim, verifica-se que o processo é um instituto constitucional, cujos destinatários são participantes ativos por meio do contraditório, ampla defesa e isonomia. As decisões prolatadas nos procedimentos devem subordinar-se à principiologia constitucional do processo. Destaque-se que não é o procedimento que legitima o procedimento, porque a racionalidade está na Constituição.

\section{PRINCÍPIOS CONSTITUCIONAIS DO PROCESSO}

Posteriormente à Segunda Guerra Mundial, os princípios constitucionais do processo passaram a ser positivados na Constituição, o que os tornaram um elemento jurídico-interpretativo de extrema relevância (ABBOUD et al., 2014, p.234).

Segundo os ensinamentos de Rosemiro Pereira Leal (2009, p.96), os referentes jurídicoexistenciais institutivos do processo são: o princípio do contraditório, o princípio da ampla defesa e o princípio da isonomia, os quais são essenciais para a definição do processo como direito-garantia constitucional para a efetivação dos direitos fundamentais por meio do procedimento processual.

Nesse norte, Aroldo Plínio Gonçalves (2001, p. 173) relata:

A primeira proteção que o ordenamento jurídico necessita oferecer aos jurisdicionados é a proteção de seu direito de, quando destinatário dos efeitos da sentença, participar dos atos que a preparam, concorrendo para sua formação, em igualdade de oportunidades.

Portanto, no Brasil, após a constituição de 1988, é impossível falar em um processo em desconformidade com a Constituição, pois o processo possui os seus alicerces em princípios constitucionais, que devem ser observados pelas leis processuais e pelos aplicadores do direito.

\subsection{Princípio do contraditório}

A Constituição Federal, no art. $5^{\circ}, \mathrm{LV}$, garante às partes o direito à ampla defesa e ao contraditório nos processos judiciais ou administrativos, bem como aos recursos cabíveis.

Elaborar um conceito acerca de um instituto jurídico é tarefa árdua, muitas vezes é preciso compreender inicialmente o que não é o instituto. Elio Fazzalari (2006, p. 356) assevera enfaticamente que o contraditório não é somente a "ciência bilateral dos atos e termos processuais, e a possibilidade de contrariá-los". Na concepção fazzalariana, "o contraditório é a participação em simétrica paridade".

Rosemiro Pereira Leal (2009, p. 97) define o contraditório da seguinte forma:

O princípio do contraditório é referente lógicojurídico do processo constitucionalizado, traduzido, em seus conteúdos, pela dialeticidade necessária entre interlocutores que se postam em defesa ou disputa de direitos alegados, podendo, até mesmo, exercer a liberdade de nada dizer (silêncio), embora tendo direito-garantia de se manifestar.

Nas lições de Aroldo Plínio Gonçalves (2001, p.115), o contraditório realizado entre as partes deve ser observado pelo juiz, por se tratar de um princípio jurídico. Dessa forma, o juiz deve garantir sua observância cumprindo e fazendo cumprir.

No direito alemão, a chamada "Anspruch auf Rechtliches Gebor" ("pretensão à tutela jurídica"), a corte constitucional manifestou-se no sentido de que essa pretensão envolve o direito de manifestação, o direito de informação sobre o objeto do processo e o direito de ver seus argumentos considerados. $\mathrm{O}$ direito de informação consiste na obrigação de informar ao adversário os atos praticados no processo e os 
elementos do ato. $\mathrm{O}$ direito de manifestação garante a oportunidade de manifestar-se por escrito ou oralmente em relação à manifestação do ex adverso. $\mathrm{O}$ direito à consideração dos argumentos assegura uma análise minuciosa por parte do julgador (MENDES et al., 2008, p. 592).

Assim, o princípio do contraditório assegura às partes a oportunidade de influenciar o provimento final, "paridade de armas". Saliente-se que há a necessidade de oportunizar o contraditório, mas se trata de uma faculdade, um ônus, e não uma obrigação. A não manifestação da parte no momento oportuno não caracteriza afronta a referido princípio, devendo a parte inerte suportar o ônus de sua omissão.

Dessa forma, o princípio do contraditório garante a participação dos litigantes e do próprio magistrado na construção do provimento jurisdicional. Caso haja necessidade de produzir determinada prova e se uma das partes for "pobre" no sentido legal, cabe ao Estado custear a produção desta, em homenagem ao princípio do contraditório.

A análise acerca da violação do contraditório ultrapassa a discussão acadêmica, pois se trata de uma garantia constitucional, sendo sua não observação uma afronta à segurança jurídica do cidadão.

Ronaldo Brêtas de Carvalho Dias (2009, p.432), ao analisar as reformas do Código de Processo Civil em face do Estado Democrático de Direito, informa que:

\footnotetext{
Se não é observada a garantia fundamental do contraditório, viga mestra do devido processo legal, este o mais importante alicerce do processo constitucional, logicamente não haverá processo, e o ato decisório não se legitimará constitucionalmente no Estado Democrático de Direito.
}

O princípio do contraditório goza de proteção normativa, obrigando o legislador a elaborar normas condizentes com essa garantia.
As normas devem ter a finalidade de atingir os meios necessários à paridade em relação às partes.

Nesse sentido, Liebman (2005, p. 195) repudia qualquer lei infraconstitucional que viole o contraditório, porque este constitui uma regra essencial do processo, que oportuniza às partes a possibilidade de influenciar a decisão final. Por isso, qualquer dispositivo infraconstitucional que viole o contraditório deve ser declarado inconstitucional.

No processo administrativo, o Ministro Marco Aurélio sustentou que, para haver a anulação do ato administrativo que tenha repercutido na esfera dos direitos individuais, é necessária a instauração do processo administrativo com observância do contraditório daqueles que serão atingidos pelo provimento. Nas palavras do relator, "o contraditório e a ampla defesa, assegurados constitucionalmente, não estão restritos apenas àqueles processos de natureza administrativa e que se mostrem próprios ao campo disciplinar. $\mathrm{O}$ dispositivo constitucional não contempla especificidades".

De forma lapidar Zaneti Júnior (2007, p. 196) conclui que o contraditório vai além da ciência bilateral dos atos e a possibilidade de contraditá-los, porque a formação procedimento prescinde da efetiva participação das partes.

Portanto, quando o provimento é construído de forma compartilhada por meio do processo administrativo ou judicial adequado e fundamentado em leis democraticamente instituídas e observando procedimentos que asseguram a imparcialidade na reconstrução do fato e do direito, podemos afirmar que a garantia do contraditório foi observada.

\subsection{Princípio da ampla defesa}

O princípio da ampla defesa abrange 
também os princípios do contraditório e da isonomia; ocorre que a defesa é feita nos limites impostos pelo contraditório.

A adição da palavra "ampla" antes de "defesa" reforça o direito do cidadão a defenderse de maneira irrestrita dentro dos limites impostos pela lei. Dessa forma, fica claro que não se pode utilizar a ampla defesa para obter dilações indevidas.

João Barbalho, em 1891, afirmava que:

Com plena defesa são incompatíveis, e, portanto, inteiramente inadmissíveis, os processos secretos, inquisitoriais, as devassas, a queixa ou depoimento de inimigo capital, o julgamento de crimes inafiançáveis na ausência do acusado ou tendo-se dado a produção de testemunhas de acusação sem ao acusado se permitir reinquiri-las, a incomunicabilidade depois da denúncia, o juramento do réu, o interrogatório dele sob coação de qualquer natureza, por perguntas sugestivas ou capciosas (CAVALCANTI, 2002).

\section{A ampla defesa assegurada pela} Constituição consiste na defesa dentro dos perímetros da necessidade, viabilidade e, evidentemente, dentro do tempo que a lei prescreve para a produção da defesa. Portanto, não há confusão entre ampla defesa e dilação indevida, podendo a última ser objeto de responsabilização das partes e do Estado-Juiz.

Rosemiro Pereira Leal (2002, p.89) define da seguinte forma a ampla defesa:

A amplitude da defesa se faz nos limites temporais do procedimento em contraditório. A amplitude de defesa não supõe a infinitude de produção de defesa a qualquer tempo, porém, que esta se produza pelos meios e elementos totais de alegações e provas no tempo processual oportunizado na lei. Há de ser ampla, porque não pode ser estreitada (comprimida) pela sumarização do tempo a tal ponto de excluir a liberdade de reflexão cômoda dos aspectos fundamentais de sua produção eficiente.

No âmbito administrativo, a Constituição de 1988 e o Supremo Tribunal Federal pacificaram o entendimento de que a ampla defesa e o contraditório são indispensáveis nos processos administrativos que tenham o objetivo de restringir direitos ou de punições disciplinares.

Vale destacar que o Código de Processo Civil português tem sido responsabilizado pela ineficiência da administração da justiça, sob o argumento de que, se a amplitude de defesa se estende em demasia, o procedimento e consequentemente a decisão final tardarão (SOUSA, 2008, p. 211).

Conforme narrado, o Código de Processo português também tem sido vítima de críticas inadequadas. É necessário indagar se é mais importante uma decisão relâmpago ou uma decisão que observe os limites e garantias constitucionais e legais. Em relação ao Brasil, mais especificamente em Minas Gerais, verificase a insuficiência de juízes, serventuários e promotores, o que inviabiliza a prestação jurisdicional em um tempo razoável.

\subsection{Princípio da isonomia}

A Revolução Francesa trouxe em seu bojo o princípio da igualdade quando houve a Declaração dos Direitos do Homem e do Cidadão, que tinha o objetivo de eliminar os privilégios de que gozavam a nobreza e o clero (TEIXEIRA, 2008, p.117).

No Estado Democrático de Direito, a isonomia busca o tratamento igual e que se possuam as mesmas chances no procedimento. Dessa forma, desde o processo legislativo deve ser observado o princípio da isonomia na aplicação da norma (CANOTILHO, 1999, p. 381-382).

Portanto, é inadmissível que a lei dispense tratamento diferente a indivíduos que se encontrem na mesma situação (MENDES et al., 2008, p. 10). Rosemiro Pereira Leal (2009, p.104) sustenta que o princípio da isonomia "não tem conteúdos de criação de direitos diferenciados pela disparidade econômica das 
partes, mas é direito assegurador de igualdade de realização construtiva do procedimento".

O supracitado autor define da seguinte forma o princípio da isonomia:

É referente lógico-jurídico indispensável do procedimento em contraditório (processo), uma vez que a liberdade de contradizer para a construção, entre as partes, da estrutura procedimental. A asserção de que há de se dar tratamento igual a iguais e desigual a desiguais resulta em tautologia inominável, porque, na estruturação do procedimento, o dizer e contradizer, em regime de liberdade assegurada em lei, não se operam pela distinção jurisdicional do economicamente igual ou desigual. $\mathrm{O}$ direito ao Processo não tem conteúdos de criação de direitos diferenciados pela disparidade econômica das partes, mas é direito assegurador de igualdade de participação construtiva do procedimento (LEAL, 2009, p. 8889).

Dessa forma, é necessário que o procedimento se desenvolva de maneira isonômica entre os participantes do processo, e que o contraditório e a ampla defesa sejam oportunizados a todos os participantes do processo. "É a estrutura processual que garante um espaço isonômico de defesa (argumentos) irrestrita (ampla defesa) [...] Nessa visão os princípios institutivos do processo (contraditório, ampla defesa e isonomia) são regências do procedimento" (ALMEIDA, 2001, p. 201).

\subsection{Considerações iniciais acerca do princípio do devido processo legal}

Para estudar a gênese do devido processo legal é necessário lançar mão dos artigos 39 e 40 da Magna Charta Libertatum, que foi outorgada pelo rei João Sem Terra no ano de 1215, na Inglaterra, quando foi positivado o princípio do process of law.

Nenhum homem livre será detido ou sujeito à prisão, ou privado de seus bens, ou colocado fora da lei, ou exilado ou de qualquer modo molestado, e nós não poderemos nem mandaremos proceder contra ele senão mediante um julgamento regular pelos seus pares ou de harmonia com a lei do país (MIRANDA, 1980, p.15).

Inicialmente, o process of law foi concebido com o intuito de limitar as ações reais; posteriormente, tornou-se uma garantia da liberdade fundamental do indivíduo e da coletividade diante do Estado (CASTRO 1999, p. 7).

Aqueles revoltados de alta linhagem que sob a liderança do arcebispo de Canterbury, Stephen Langton, conquistaram a aposição do selo real naquela autêntica declaração dos direitos da nobreza inglesa frente à coroa, jamais poderiam cogitar que nesse dia 15 de junho do ano de 1215 se estava lançando aos olhos da história da civilização a sementeira de princípios imorredouros, como o da "conformidade com as leis", o do "juízo natural", o da "legalidade tributária" e o instituto do habeas corpus. A bem dizer, ao lado da "igualdade perante a lei" (e qual protection of the law). A cláusula due process of Law erigiu-se no postulado maior da organização social e política dos povos cultos na era moderna (CASTRO, 1999, p. 7).

Ainda com relação a Magna Charta Libertatum, vale ressaltar que esta parece ser a fonte mais antiga de controle do poder público, excetuando-se apenas a democracia Grega, que apesar de diversos contornos históricos, sempre esteve fundamentalmente ligada ao controle do poder público (ZANETI JÚNIOR, 2007, p.12).

No direito americano, o devido processo legal foi incluído pela $\mathrm{V}$ emenda à Constituição. Em seguida, foi aprovada a XIV emenda, que ampliou a abrangência para abarcar a vida, liberdade e propriedade (LIMA 2007, p.241).

Posteriormente à análise das Constituições brasileiras de 1824,1891,1934,1937,1946, 1967 ,1969 e 1988, observa-se que a única que traz o princípio do devido processo legal de maneira expressa é a Constituição de 1988, o que, consequentemente, 
causou o rompimento com o dogmatismo processual. O devido processo legal é um princípio inserido em uma Constituição democrática arrimada no Estado Democrático de Direito (LIMA, 2007, p. 242).

Portanto, verifica-se que a inserção do princípio do devido processo legal no direito brasileiro ocorreu tardiamente, o que sem dúvida demonstra que historicamente havia pouca preocupação com a observância das regras para a validade do procedimento, o que possivelmente atendia aos interesses de uma classe dominante.

2.4.1 O princípio do devido processo legal na Constituição Federal de 1988

O princípio do devido processo legal encontra-se no art. $5^{\circ}, \mathrm{LIV}$, entre os direitos e garantias fundamentais elencados na Constituição Federal de 1988. Há uma ligação direta entre a ampla defesa e o contraditório, que devem ser respeitados, conforme preconiza o texto constitucional.

Nesse norte, Rui Portanova (1997, p.145) analisa o devido processo legal sob duplo ponto de vista: o primeiro é a garantia constitucional do acesso ao poder judiciário, e o segundo é o desenvolvimento processual respeitando as normas processuais previamente estabelecidas.

Por sua vez, Ronaldo Brêtas de Carvalho Dias faz as seguintes observações em relação às alterações trazidas pela emenda 45 , e propõe um conceito atualizado do princípio do devido processo legal:

O devido processo legal, agora, segundo a Constituição, sob interpretação lógico-sistemática, com o acréscimo do inciso LXVIII ao art. $5^{\circ}$, desponta como um bloco aglutinante e compacto de várias garantias fundamentais ostentadas pelas partes litigantes contra o Estado, quais sejam: a) de amplo acesso à jurisdição, prestada em tempo útil ou lapso temporal razoável; b) do juízo natural; c) do contraditório; d) da plenitude de defesa, com todos os meios e recursos a ela (defesa) inerentes, aí incluído o direito ao advogado ou ao defensor público (arts. 133 e 134); e) da fundamentação racional das decisões jurisdicionais (art.93, incisos IX e X); f) de um processo sem dilações indevidas (DIAS, 2006, p. 293).

Portanto, o princípio do devido processo legal é uma garantia constitucional que assegura aos cidadãos a proteção à liberdade e aos bens, sendo permitida a sua violação somente após a observância das normas processuais previamente estabelecidas, e após a emenda 45 se deve garantir também a celeridade e a duração razoável do processo.

Acrescenta Ronaldo Brêtas de Carvalho Dias (2006, p. 656) acerca das restrições às garantias do devido processo legal:

A restrição de quaisquer dessas garantias
processuais constitucionais, sob a justificativa de
agilizar ou tornar célere o procedimento, revela-se
inconstitucional e antidemocrática, somente
servindo para estimular o arbítrio dos juízes,
fomentar a insegurança jurídica e escarnecer da
garantia fundamental do devido processo legal, em
resumo, deslavada e grosseira agressão ao princípio
constitucional do Estado Democrático.

Indignado com a manutenção do sistema inquisitorial do Código de Processo Penal brasileiro, diante da vigência da Constituição de 1988, Jacinto Nelson diz que, se houvesse "vergonha", já teria sido revisto esse sistema, em observância ao princípio do devido processo legal (NELSON, 2009, p. 222-223).

Verificou-se com a pesquisa que mesmo após décadas de vigência da Constituição de 1988, ainda vigoram no Brasil leis procedimentais que violam o devido processo legal, como por exemplo o inquérito policial, o qual prescinde da realização do devido processo legal.

\section{CONCLUSÕES}

Posteriormente ao estudo do processo constitucional no Estado Democrático de Direito,é possível alinhar as seguintes 
conclusões:

O processo é um instituto constitucional do qual os participantes atuam ativamente para a construção do provimento por meio de seus princípios (devido processo legal, contraditório, ampla defesa e isonomia). Ademais, qualquer decisão que deixe de observar estes princípios é inconstitucional, e devem ser cassadas ou reformadas.

O devido processo legal consiste na observância de todos os princípios constitucionais-processuais, sem os quais, conforme estudado inexiste o processo, e o provimento torna-se ilegítimo.

Já o contraditório e a ampla defesa se complementam no sentido de que deve ser oportunizado à parte adversa se defender e se opor a todas as imputações que lhe forem atribuídas, enquanto ao magistrado cabe observar e assegurar o cumprimento desses princípios, bem como enfrentar os argumentos suscitados na decisão. Por fim, a isonomia decorre do tratamento igualitário às partes integrantes do processo.

\section{REFERÊNCIAS}

ABBOUD, Georges; CARNIO, Henrique Garbellini; OLIVEIRA, Rafael Tomaz de. Introdução à teoria e à filosofia do direito. 2. ed. rev. atual. ampl. São Paulo: Revista dos Tribunais, 2014.

ALEXY, Robert. Teoria dos direitos fundamentais. Trad. Virgílio Afonso da Silva. São Paulo: Malheiros, 2008.

ALMEIDA, Andréa Alves de. A efetividade, eficiência e eficácia do processo no Estado Democrático de Direito. In: LEAL, Rosemiro Pereira (Coord.). Estudos continuados de teoria do processo. Porto Alegre: Síntese, 2001. v. 4, cap. I.

ALMEIDA, Andréa Alves de. Processualidade jurídica e legitimidade normativa. Belo Horizonte: Fórum, 2005.

ANANIAS, Patrus. Processo constitucional e devido processo legal na Constituição de 1824. Dissertação (mestrado) - Pontifícia Universidade Católica de Belo Horizonte-MG. Programa de pós em Direito. Belo Horizonte, 2010.

ANDOLINA, Italo. O papel do processo na atuação do ordenamento constitucional e transnacional. Revista de Processo, v.87, p. 63-69, São Paulo, jul./set.1997.

ANDOLINA, Italo; VIGNERA, Giuseppe. I fondamenti costituzionali della giustizia civile: il modelo costituzionale Del processo civile italiano. Seconda edizione ampliata e aggiornata. Torino: Giappichelli, Editore, 1979.

ÁVILA, Humberto. Teoria dos princípios. 10. ed. São Paulo: Malheiros, 2009.

BARACHO, José Alfredo de Oliveira. Teoria geral do processo constitucional. Revista da Faculdade Mineira de Direito, v.2, n.3 e 4, p. 89-154, Belo Horizonte, $1^{\circ}$ e $2^{\circ}$ sem.1999.

BARACHO, José Alfredo de Oliveira. Processo constitucional: aspectos contemporâneos. Belo Horizonte, Fórum, 2006.

BARROS, Flaviane de Magalhães. O modelo constitucional de processo e o processo penal: a 
necessidade de uma interpretação das reformas do processo penal a partir da Constituição. In: MACHADO, Felipe Daniel Amorim; CATTONI DE OLIVEIRA, Marcelo Andrade (Coords.). Constituição e processo: a contribuição do processo ao constitucionalismo brasileiro. Belo Horizonte: Del Rey, 2009.

BONAVIDES, Paulo. Curso de direito constitucional. 13. ed. rev. atual. São Paulo: Malheiros, 2002.

CANOTILHO, José Joaquim Gomes. Direito constitucional e teoria da Constituição. 3. ed. Coimbra: Almedina, 1999.

CASTRO, Carlos Roberto de Siqueira. O devido processo legal e a razoabilidade das leis na nova Constituição do Brasil. 2.ed. Rio de Janeiro, Forense, 1999.

CATTONI DE OLIVEIRA, Marcelo de Andrade. Direito processual constitucional. Belo Horizonte: Mandamentos, 2001.

CAVALCANTI, João Barbalho Uchoa. Constituição Federal brasileira (1891). Brasília: Senado Federal, 2002

COUTURE, Eduardo. Fundamentos del derecho procesal civil. Buenos Aires: Depalma, 1974.

DIAS, Ronaldo Brêtas de Carvalho. Responsabilidade do Estado pela função jurisdicional. Belo Horizonte: Del Rey, 2004.

DIAS, Ronaldo Brêtas de Carvalho. Fundamentos do Estado Democrático de Direito. Revista da Faculdade Mineira de Direito, v. 7, n. 13 e 14, p. 150-163, Belo Horizonte, $1^{\circ}$ e $2^{\circ}$ sem. 2004.

DIAS, Ronaldo Brêtas de Carvalho. A garantia da fundamentação das decisões jurisdicionais no Estado Democrático de Direito. Revista da Faculdade Mineira de Direito, v. 8, n. 16, p.147-161, Belo Horizonte, $2^{\circ}$ sem. 2005.

DIAS, Ronaldo Brêtas de Carvalho. Direito à jurisdição eficiente e garantia da razoável duração do processo no Estado Democrático de Direito. In: GALUPPO, Marcelo Campos (Org.). O Brasil que queremos: reflexões sobre o Estado Democrático de Direito. Belo Horizonte: Editora PUC/Minas, 2006.

DIAS, Ronaldo Brêtas de Carvalho. Exame técnico e sistemático do Código de Processo Civil. In: DIAS, Ronaldo Brêtas de Carvalho; DINIZ NEPOMUCENO, Luciana (Coords.). Processo civil reformado. Belo Horizonte: Del Rey, 2009.

DIAS, Ronaldo Brêtas de Carvalho. As reformas do Código Processo Civil e o processo constitucional. In: DIAS, Ronaldo Brêtas de Carvalho; DINIZ NEPOMUCENO, Luciana(Coords.). Processo civil reformado. Belo Horizonte: Del Rey, 2009.

DIAS, Ronaldo Brêtas de Carvalho. Fundamentos constitucionais da jurisdição no Estado Democrático de Direito. In: GALUPPO, Marcelo Campos (Coord.). Constituição e democracia: fundamentos. Belo Horizonte: Fórum, 2009.

DIDIER JÚNIOR, Fredie. Curso de direito processual civil. Salvador: Jus podivm, 2015. v.1 
FAVOREU, Louis. As Cortes Constitucionais [Les Cours Constitutionelles]. Trad. Dunia Marinho Silva. São Paulo: Landy, 2004.

FAZZALARI, Elio. Instituições de direito processual. Trad. Elaine Nassif. Campinas: Bookseller, 2006.

GONÇALVES, Aroldo Plínio. Técnica processual e teoria do processo. 2. tir. Rio de Janeiro: AIDE, 2001.

GUERRA FILHO, Willis Santiago. Princípio da proporcionalidade e devido processo legal. In: SILVA, Virgílio Afonso da (Org.). Interpretação constitucional. São Paulo: Malheiros, 2005.

LEAL, André Cordeiro. O contraditório e a fundamentação das decisões no direito processual democrático. Belo Horizonte: Mandamentos, 2002.

LEAL, Rosemiro Pereira. Teoria da decisão jurídica. São Paulo: Landy, 2002.

LEAL, Rosemiro Pereira. Modelos processuais e Constituição democrática. In: MACHADO, Felipe Daniel Amorim; CATTONI DE OLIVEIRA, Marcelo Andrade (Coords.). Constituição e processo: a contribuição do constitucionalismo brasileiro. Belo Horizonte: Del Rey, 2009.

LEAL, Rosemiro Pereira. Teoria geral do processo: primeiros estudos.9. ed. rev. e ampl. Rio de Janeiro: Forense, 2009.

LIEBMAN, Enrico Tullio. Manual de direito processual civil. 3.ed. Trad. e notas Cândido Rangel Dinamarco. São Paulo: Malheiros,2005.

LIMA, Juliano Vitor. Do princípio do devido processo legal. In: TAVARES, Fernando Horta (Coord.). Constituição, direito e processo. Curitiba: Juruá, 2007.

MAC-GREGOR, Eduardo Ferrer. Es Kelsen el fundador del derechos procesal constitucional? Análisis de un debate contemporâneo. Revista de Processo, v. 164, p. 245-282, São Paulo: out. 2008.

MENDES, Gilmar Ferreira. Direitos fundamentais e controle de constitucionalidade.3. ed. rev. ampl. 3. tir. São Paulo: Saraiva, 2007.

MENDES, Gilmar Ferreira; MÁRTIRES COELHO, Inocêncio; GONET BRANCO, Paulo Gustavo. Curso de direito constitucional. 2. ed. São Paulo: Saraiva, 2008.

MIRANDA, Jorge. Textos históricos do direito constitucional. Lisboa: Imprensa Nacional/Casa da Moeda, 1980.

MITIDIEIRO, Daniel. Processo civil e estado constitucional. Porto Alegre: Livraria do Advogado. 2007.

MITIDIEIRO, Daniel. A colaboração como norma fundamental do novo Processo Civil. Revista do Advogado. n 126. p. 47-52. 2015

MONTENEGRO FILHO, MISAEL. Curso de direito processual civil. São Paulo: Atlas, 2015. 
MÜLLER, Friedrich. Métodos de trabalho do direito constitucional. Trad. Peter Naumann. 3. ed. rev. e ampl. Rio de Janeiro: Renovar, 2005.

NELSON, Jacinto. A contribuição da Constituição democrática ao processo penal inquisitório brasileiro. In: MACHADO, Felipe Daniel Amorim; CATTONI DE OLIVEIRA, Marcelo Andrade (Coords.). Constituição e processo: a contribuição do processo ao constitucionalismo brasileiro. Belo Horizonte: Del Rey, 2009.

PORTANOVA, Rui. Princípios do processo civil. Porto Alegre: Livraria do Advogado, 1997.

SILVA, José Afonso da. Ação popular constitucional. 2. ed. rev. ampl. e aum. São Paulo: Malheiros, 2007.

SOARES, Carlos Henrique. O advogado e o processo constitucional. Belo Horizonte: Decálogo, 2004.

SOUSA, Miguel Teixeira de. Um novo processo civil português: à la recherche Du temps perdu?. Revista de Processo, v. 5, p.203-220, São Paulo: jul. 2008.

THEODORO JÚNIOR, Humberto. Constituição e processo. Revista do Instituto dos Advogados Mineiros, v.15, p. 341-375, Belo Horizonte, 2009.

TEIXEIRA, Welington Luzia. Da natureza jurídica do processo à decisão judicial democratizada. Belo Horizonte: Fórum, 2008.

TUCCI, Rogério Lauria. Direitos e garantias individuais no processo penal brasileiro. 2. ed. rev. e atual. São Paulo: Revista dos Tribunais, 2004.

VARGAS, José Cirilo de. Processo penal e direitos fundamentais. Belo Horizonte: Del Rey, 1992.

ZANETI JÚNIOR, Hermes. Processo constitucional: o modelo constitucional do processo civil brasileiro. Rio de Janeiro: Lumen Juris, 2007.

Recebido em: 15/12/2016

Aceito em: 12/02/2017 
